\title{
Central Nervous System Vasculitis Complicating Rheumatoid Arthritis in a Patient on a TNF Inhibitor: a Causal Association? Case Report and Systematic Review
}

Adam Joseph Brown*, Susan M Staugaitis, Alex Wu, Leonard H. Calabrese

Cleveland Clinic, Cleveland, Ohio, United States

*Corresponding Author: Adam Joseph Brown, M.D. Cleveland Clinic Cleveland, OH United States, Tel.: 216 4442200; E-mail: browna22@ccf.org

Received date: December 7, 2015; Accepted date: February 22, 2016; Published date: February 29, 2016

Copyright: (C) 2016 Brown AJ et al. This is an open-access article distributed under the terms of the Creative Commons Attribution License, which permits unrestricted use, distribution, and reproduction in any medium, provided the original author and source are credited.

\section{Introduction}

Primary Angiitis of the Central Nervous System (PACNS) is a rare disease that causes inflammation and destruction of the vessels within the CNS without evidence of a systemic vasculitis process. There is little known about the etiology of this disease entity but there are a limited number of case reports of CNS vasculitis being associated with biologic therapies in particular TNF antagonists [1]. TNF antagonists have been in use for over 20 years for the treatment of numerous immunologic diseases. It is estimated that over 3 million people have been exposed to these drugs [2].

While TNF antagonists are known for their association with numerous adverse events, in particular opportunistic infections and malignancies, they have also been associated with the development of numerous autoimmune diseases [1]. TNF antagonists have rarely been associated with the development of vasculitis. The largest case series evaluating the association of TNF antagonists and vasculitis was done by Ramos et al who reviewed 233 cases of vasculitis associated with TNF antagonists. The vast majority of the cases reported (87\%) were primary cutaneous vasculitis [1]. Many of these associations have been established by cutaneous resolution after withdrawal of the medication (ie challenge, dechallenge). In this case series visceral involvement of vaculitis is less common at $24 \%$ [1]. There are even fewer examples of anti-TNF agents being associated with a primary CNS vasculitis $4 \%$, and none of the cases in this study were biopsy proven [1]. Here we present a case of a biopsy proven CNS vasculitis developing in a patient with rheumatoid arthritis (RA) while taking etanercept with a systematic review of the literature regarding TNF antagonists and CNS vasculitis.

Keywords CNS Vasculitis; Primary Angiitis of the CNS; TNF Inhibitor; Infliximab; Etanercept; Adalimumab; Golimumab; Certolizumab Pegol.

\section{Case Report}

A 47-year-old male with history of seropositive, erosive rheumatoid arthritis developing in his mid-30s presented for evaluation of multiple neurologic symptoms, including face and tongue numbness and left arm weakness. His RA was diagnosed 15 years prior to his presentation and treated with etanercept for the last 7 years with good control of his symptoms until his current presentation. An MRI of his brain showed an area of increased signal intensity on T2 and FLAIR images in the right frontal region (Figure 1). Etanercept was stopped because of concern of a possible demyelinating process. Of note, three months prior to his neurologic presentation he reported developing a rash diagnosed as shingles by his primary care physician for which he was treated with acyclovir and taken off etanercept for 2 weeks.

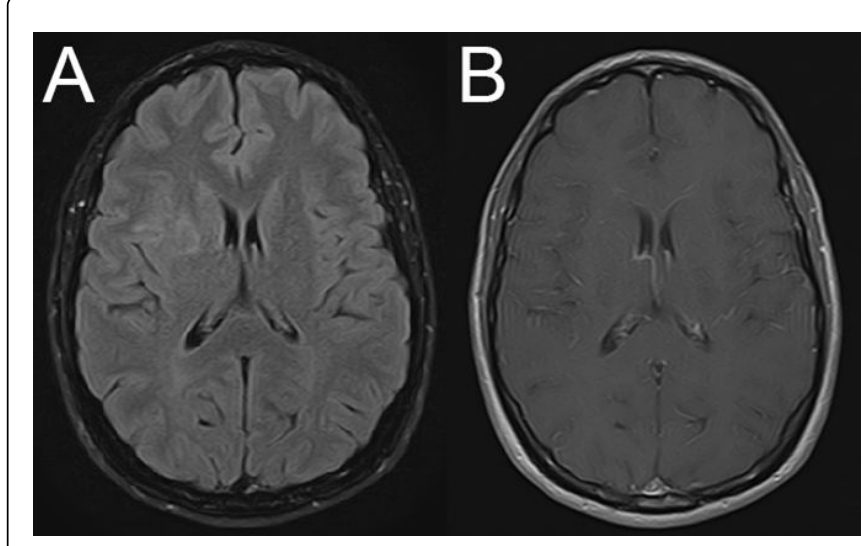

Figure 1: FLAIR (A) and Gadolinium enhanced T1 (B). Initial FLAIR (A) demonstrates subtly increased subcortical and deep white matter signal about the right frontal lobe and frontal operculum without corresponding enhancement on gadolinium enhanced $\mathrm{T} 1$ acquisition (B).

A repeat MRI 3 months after the first showed the lesion had increased in size and measured nearly $3 \mathrm{~cm}$ (Figure 2). He was seen by numerous neurologists and neurosurgeons, and the brain lesion was thought to likely represent malignancy. A biopsy and excision was performed which showed inflammation and necrotizing granulomas consistent with vasculitis (Figure 3). Glucocorticoids were initiated at the outside hospital and his symptoms improved. One month later (while on glucocorticoids) an LP was performed and his CSF revealed normal protein and white blood cell count, negative cultures including PCR for VZV. He was referred to the Cleveland Clinic for further evaluation. At this point he was on prednisone $15 \mathrm{mg}$ daily and his etanercept continued to be held as it was thought the CNS vasculitis could be secondary to the anti-TNF therapy. He was started empirically on acyclovir for concern of VZV vasculopathy considering his shingles outbreak prior to his presentation. Immunostains for VZV were performed on his brain biopsy at two different laboratories (Cleveland Clinic and University of Colorado courtesy of Donald Gilden MD) and were negative. Initially his symptoms and imaging were stable on prednisone $15 \mathrm{mg}$ and holding etanercept; however, 9 months after the first MRI his symptoms began to return and an MRI showed a new small lesion. His prednisone was increased to $50 \mathrm{mg}$ and he was initiated on oral cyclophosphamide $(2 \mathrm{mg} / \mathrm{kg})$. Cyclophosphamide was discontinued after 3 months because of elevated liver enzymes and azathioprine was initiated once liver enzymes improved. Repeat MRI showed a slight enlargement of the 
Citation: Brown AJ, Staugaitis SM, Wu A and Calabrese LH (2016) Central Nervous System Vasculitis Complicating Rheumatoid Arthritis in a Patient on a TNF Inhibitor: a Causal Association? Case Report and Systematic Review. J Vasc 1: 104. doi:10.4172/2471-9544.100104

Page 2 of 4

brain lesion and he was pulsed with methylprednisolone (1,000 mg IV/ daily $\mathrm{x} 3$ days). Since this time his symptoms and imaging have been stable nearly 2 years after symptom onset.

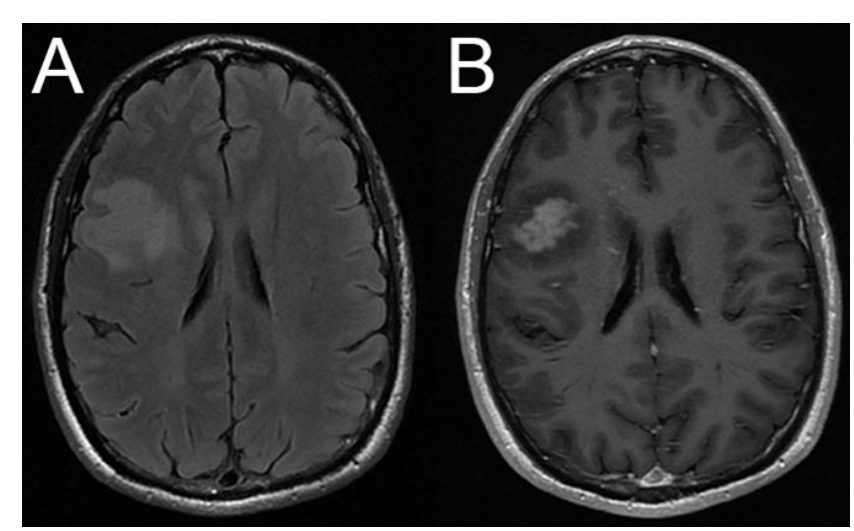

Figure 2: FLAIR (A) and Gadolinium enhanced T1 (B). At 3 month follow up, there is interval progression with a hyperintense masslike lesion on FLAIR (A) with central enhancement on gadolinium enhanced T1 (B) at the right middle frontal gyrus extending to the frontal operculum and local mass effect with effacement of the right lateral ventricle.
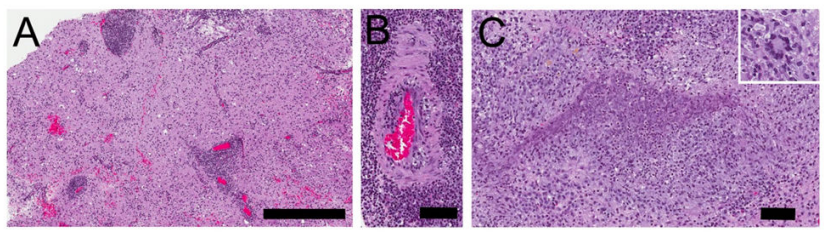

Figure 3: Brain biopsy showing vasculitic pathology. (A) Low magnification image of brain biopsy showing multiple foci of perivascular inflammation. (B) High magnification of an arteriole showing inflammatory cells within the vessel wall. (C) Granuloma consisting of a rim of lymphocytes, epithelioid histiocytes, and plasma cells with central necrotic focus. The background parenchyma showed vacuolization and hypertrophied astrocytes consistent with ischemic injury. There was no evidence of neoplasm or infection by routine stain. A multinucleated giant cell is shown in the inset. Scale bars: $500 \mu \mathrm{m}$ for panel A, and $100 \mu \mathrm{m}$ for panels B and $\mathrm{C}$.

\section{Methods}

A comprehensive literature review of all English full-text articles published through October 2015 was performed using PubMed, EMBASE and Medline. The following search entries were used: "Etanercept" OR "Infliximab" OR "Adalimumab" OR "Golimumab" OR "Certolizumab Pegol" AND "Primary Angiitis of the Central Nervous System" OR "CNS Vasculitis". The combined search revealed 38 articles, which were reviewed and relevant information was extracted, as well as information from articles cited in the reference section of the retrieved articles. In addition to this literature search, each pharmaceutical company making FDA approved TNF inhibitors was contacted directly and asked to release reports in the public domain of patients that developed CNS vasculitis while on their respective biologic .

\section{Systematic Review of the Literature:}

Despite a systematic review of the literature searching for anti-TNF therapy associated with central nervous system vasculitis development, few examples were encountered (see Table 1). A case series of 8 patients who developed vasculitis while on a TNF antagonist described one patient on infliximab who developed slurred speech, a lumbar puncture was normal but an MRI showed focal areas of ischemia in the posterior putamen. A diagnosis of cerebral ischemia possibly of vasculitic origin was made but without pathologic confirmation [3]. A retrospective series from France describes 39 patients who developed vasculitis while on anti-TNF therapy including 3 cases of possible CNS involvement that are listed. The first patient had central retinal vein occlusion. The second patient developed episodes of confusion of unknown etiology, but no LP or imaging results are listed. The third patient experienced seizure activity at the time of diagnosis of a systemic vasculitis, but again, no mention of LP or imaging study [4]. In another case report, a patient developed VZV multifocal CNS vasculopathy while taking adalimumab which was fatal. No biopsy was done in this case; the diagnosis was made based on clinical presentation, CSF analysis and imaging findings [5]. Another case involved the use of adalimumab in a patient with Crohn's disease which resulted in a drug induced lupus (+ANA, + DS-DNA Ab) with neurologic symptoms and a brain lesion on MRI consistent with a vasculitis. The patient's symptoms and lesion on imaging responded to steroids and withdrawal of adalimumab, but the CNS lesion was not biopsy proven [6].

\begin{tabular}{|l|l|l|l|l|l|l|l|}
\hline Case & Reference & TNF & $\begin{array}{l}\text { Disease } \\
\text { Treated }\end{array}$ & Symptoms & MRI & LP & Biopsy \\
\hline 1 & $\begin{array}{l}\text { Stephen J. } \\
\text { Jarrett et al } \\
2003(3)\end{array}$ & Infliximab & RA & Slurred speech & Ischemia of posterior putamen & Normal & Not done \\
\hline 2 & $\begin{array}{l}\text { Bernadett } \\
\text { Saint } \\
\text { Marcoux et } \\
\text { al 2006 (4) }\end{array}$ & NA & NA & NA & Central retinal vein occlusion & NA & Not done \\
\hline
\end{tabular}




\begin{tabular}{|c|c|c|c|c|c|c|c|}
\hline 3 & $\begin{array}{l}\text { Bernadett } \\
\text { Saint } \\
\text { Marcoux et } \\
\text { al } 2006(4)\end{array}$ & NA & NA & $\begin{array}{l}\text { Episode of } \\
\text { confusion }\end{array}$ & NA & NA & Not done \\
\hline 4 & $\begin{array}{l}\text { Bernadett } \\
\text { Saint } \\
\text { Marcoux et } \\
\text { al } 2006(4)\end{array}$ & NA & NA & $\begin{array}{l}\text { Seizure at time } \\
\text { of diagnosis of } \\
\text { systemic } \\
\text { vasculitis }\end{array}$ & NA & NA & Not done \\
\hline 5 & 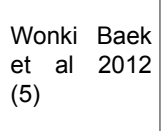 & Adalimumab & RA & $\begin{array}{l}\text { Mental } \\
\text { obtundation }\end{array}$ & $\begin{array}{l}\text { Multifocal parenchymal lesions } \\
\text { and hemorrhage in the } \\
\text { brainstem and supratentorial } \\
\text { areas. }\end{array}$ & $\begin{array}{l}\text { WBC } 150 \text { cell/ } \\
\text { mm3, } 72 \% \\
\text { Lymphocytes, } \\
\text { protein } 330 \mathrm{mg} / \mathrm{dL}\end{array}$ & Not done \\
\hline 6 & $\begin{array}{l}\text { Vieri } \\
\text { Vannucchi et } \\
\text { al } 2010(6)\end{array}$ & Adalimumab & Crohns & $\begin{array}{l}\text { Nuchal } \\
\text { headache, } \\
\text { dizziness and } \\
\text { right superior } \\
\text { quadrantopsy }\end{array}$ & $\begin{array}{l}\text { Bilateral occipital serpiginous } \\
\text { lesions and infarct in right } \\
\text { cerebellar hemisphere. }\end{array}$ & Normal & Not done \\
\hline 7 & $\begin{array}{l}\text { Núria } \\
\text { Caballol } \\
\text { Pons et al } \\
2010(7)\end{array}$ & Adalimumab & RA & $\begin{array}{l}\text { Headache and } \\
\text { dysarthria }\end{array}$ & $\begin{array}{l}\text { White matter enhancement of } \\
\text { right fronto-parietotemporal } \\
\text { lobes with right meningeal } \\
\text { gadolinium enhancement. }\end{array}$ & NA & $\begin{array}{l}\text { "Necrotizing and lymphocytic vasculitis } \\
\text { in both meningeal and cerebral } \\
\text { parenchyma, with lymphocytic cell } \\
\text { infiltration involving all layers of the } \\
\text { vessel wall7" }\end{array}$ \\
\hline 8 & $\begin{array}{l}\text { Present } \\
\text { Case }\end{array}$ & Etancercept & RA & $\begin{array}{l}\text { Face/tongue } \\
\text { numbness and } \\
\text { left } \quad \text { arm } \\
\text { weakness }\end{array}$ & Hyper intense mass lesion & $\begin{array}{l}\text { Normal } \\
\text { glucocorticoids) }\end{array}$ & $\begin{array}{l}\text { "...necrotizing granulomatous and } \\
\text { vasculitic pathology" }\end{array}$ \\
\hline
\end{tabular}

Table 1: Case series of 8 patients who developed vasculitis while on a TNF antagonist.

\section{Public Domain Information from Pharmaceutical Industry}

Abbvie provided multiple case reports of patients who developed vasculitis while on adalimumab, but only one of the cases reported CNS involvement. The case occurred in a 71 year old female with long standing rheumatoid arthritis, she was on adalimumab for 1 year when she presented with hemiparesis and dysarthria. Gadolinium-enhanced magnetic resonance imaging showed an extensive "high-intensity image in $\mathrm{T} 2$ and FLAIR-weight sequences in the frontoparietotemporal lobes with right meningeal gadolinium enhancement". A brain biopsy revealed transmural inflammation consistent with vasculitis [7]. The patient was treated with high dose glucocorticoids and made a full recovery. The article does not mention whether or not adalimumab was held at the time of diagnosis [7].

Amgen, the makers of etanercept presented a list of case reports of patients who subsequently developed a vasculitis in association with therapy but none of these were CNS vasculitis. There is one report of a patient who developed isolated injection site cutaneous vasculitis and subsequent paresthesias of her legs and intermittent diplopia while on etanercept and brain MRI showed evidence of demyelination [8].

Janssen provided multiple cases and case series of vasculitis associated with the use of biologics but all of the papers were found in the initial literature search.

UCB responded with a letter mentioning vasculitis occurring in patients with Crohn's disease while on certalizumab pegol but no mention of cases involving the CNS.

\section{Discussion}

The current case represents one of a man with long standing seropositive, erosive RA with a paucity of extra-articular features who developed isolated biopsy proven CNS vasculitis while on a TNF inhibitor (etanercept). While this case may represent a second and seemingly unrelated confounding disorder (i.e. Primary Angiitis of the CNS in the setting of RA), two other diagnostic considerations deserve critical appraisal, namely CNS vasculitis secondary to the TNF inhibitor or CNS vasculitis as a complication of RA.

It is possible that the CNS angiitis is indeed an extra-articular complication of his RA but the evidence is weak. There are case reports of systemic rheumatologic diseases with subsequent development of CNS vasculitis including RA [7,9] but such complications are exceeding rare, and there is no definitive way to prove or disprove this. In a case report and literature review of CNS vasculitis associated with RA by Pons et al, 12 cases are found. In only one of these cases was a TNF antagonist being used to treat the RA prior to development CNS symptoms [7]. Most cases have been described in the setting of long standing disease often in association with other extra-articular features. In contradistinction to the characteristic pathology of rheumatoid nodules within the meninges the histopathology of cases of CNS vasculitis with granulomatous inflammation primarily involving the brain parenchyma has been non-specific [10].

The second possibility is that the CNS vasculitis represents a complication of concomitant TNF inhibitor exposure. As with virtually all untoward drug adverse effects causality is difficult to prove in the absence of a positive dechallenge and rechallenge of the drug, a maneuver rarely attempted for ethical reasons. Based on the widely described association of TNF inhibitor therapy and peripheral (largely cutaneous) vasculitis [1] we thought it valuable to conduct a systematic 
review to address the question of the possible causal association between TNF inhibitors and CNS vasculitis.

There have been over 500 reported cases of CNS vasculitis since 1959 [11], but only 8 case reports of patients developing a CNS vasculitis while on a TNF antagonist including this one. A careful review of such cases revealed that the majority were diagnosed based on symptoms and imaging changes and not biopsy proven.

These cases are summarized in Table 1. Although Case 1 has MRI findings concerning for infarcts the patient had a normal LP. Two of the cases have no mention of MRI findings and 4 cases have no mention of the CSF analysis. Of the 4 cases with objective evidence (Imaging findings, LP, biopsy), two were confounded as one was in the setting of a new diagnosis of drug induced lupus, and the other in the setting of VZV vasculopathy. Case 7 presents sufficient evidence demonstrating CNS vasculitis in the setting of adalimumab therapy but the paper does not mention whether adalimumab was discontinued during treatment for the vasculitis making it is difficult to know if there is an association.

On review of the literature there is only one case report other than the one presented here, with sufficient evidence confirming the diagnosis of primary CNS vasculitis associated with anti-TNF therapy [7]. Our systematic querying of the manufacturers of all commercially produced TNF inhibitors also was unrevealing, although there are many cases of vasculitis associated with TNF inhibitors, very few involved the CNS. Considering the limited data it appears CNS vasculitis is exceedingly rare in the setting of biologic therapy.

Unlike the experience with cutaneous vasculitis and biologic therapy where there is evidence of causality because of documented challenge and de-challenge of biologics and subsequent resolution of lesions, no such evidence exists at this time for CNS vasculitis and biologic therapy. We present a well-documented case of biopsy proven CNS vasculitis in the setting of biologic therapy that did not resolve with discontinuation of the biologic, at this juncture there is no evidence for causality of biologic therapy and CNS vasculitis.

\section{References}

1. Ramos-Casals M, Brito-Zerón P, Muñoz S, Soria N, Galiana D, et al (2007) Autoimmune Diseases Induced by TNF-Targeted Therapies Analysis of 233 Cases. Medicine (Baltimore) 86: 242-51

2. Calabrese LH, Molloy E, Berger J (2015) Sorting out the risks in progressive multifocal leukoencephalopathy. Nat Rev Rheumatol 11: 119-123.

3. Jarrett SJ, Cunnane G, Conaghan PG, Bingham SJ, Buch MH, et al. (2003) Anti-tumor necrosis factor-alpha therapy-induced vasculitis: case series. J Rheumatol 30: 2287-2291.

4. Saint Marcoux B, De Bandt M; CRI (Club Rhumatismes et Inflammation) (2006) Vasculitides induced by TNFalpha antagonists: a study in 39 patients in France. Joint Bone Spine 73: 710-713.

5. Baek W, Lee SG, Kim YS, Kim JH, Jun JB, et al. (2012) Fatal varicellazoster virus vasculopathy associated with adalimumab therapy. Arch Neurol 69: 1193-1196.

6. Vannucchi V, Grazzini M, Pieralli F, Giannotta M, Biagioni C, et al. (2011) Adalimumab-induced lupus erythematosus with central nervous system involvement in a patient with Crohn's disease. J Gastrointestin Liver Dis 20: 201-203.

7. Pons C, Montala N, Valverde J, Brell M, Ferrer I, et al. (2010) Isolated cerebral vasculitis associated with rheumatoid arthritis. Joint Bone Spine 77: 361-363.

8. Martínez-Taboada VM, Val-Bernal JF, Pesquera LC, Fernández-Llanio NE, Esteban JM et al. (2006) Demyelinating disease and cutaneous lymphocitic vasculitis after etanercept therapy in a patient with rheumatoid arthritis. Scand J Rheumatol 35: 322-323.

9. Spath NB, Amft N, Farquhar D (2014) Cerebral vasculitis in rheumatoid arthritis. QJM 107: 1027-1029.

10. Hajj-Ali RA, Calabrese LH (2014) Diagnosis and classification of central nervous system vasculitis. J Autoimmun 48-49: 149-52.

11. Hajj-Ali RA, Singhal AB, Benseler S, Molloy E, Calabrese LH (2011) Primary angiitis of the CNS. Lancet Neurol 10: 561-572. 